\title{
Influence of Anaesthesia on Blood Loss During Prostatic Resection
}

\author{
7 AHSAN P J ENGLISH R CARTNER R. MITCHELL F.A. ZAEEM \\ Departments of Lrology. Haematology and Anaesthesia. University Hospital of North Durham. Durham. UK and Urology \& Kidney Transplant \\ 1) Darlment of F... Medical college/Sir Ganga Ram Hospital, Lahore. Pakistan.

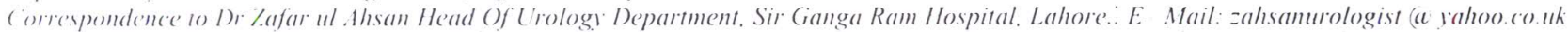

\begin{abstract}
Objective: The volume of blood loss during prostatic resection (TURP) is determined by a number of factors. The aim of the present study was to ascertain the independent effect of a general or a spinal anaesthetic on the amount of intraoperative blood loss. Patients and methods: A total of 110 patients treated by TURP, were entered in to a prospective study. The mean age of the patients was 71 years (range $45-91$ ). Sixty-six patients (60\%) received a spinal and $44(40 \%)$ had a general anaesthetic ; $80 \%$ of resections were benign and $20 \%$ for malignant disease. The mean resected weight was 29.7 grams (range 3-100) and the mean resection time was 28.9 minutes (range $5-60$ ). The volume of blood loss was calculated by a well described method and the mean loss was 319mls (range 6 - 1587). Results: The mean weight of the resected prostate tissue and the volume of blood loss was significantly high in patients who had received a spinal anaesthetic $(p=0.001$ and $p=0.005$ respectively). However, when the independent influence of the type of anaesthesia and the resected weight on blood loss was analysed, it was found that the former had no significant effect $(p=0.28)$ whereas the later influenced very significantly $(\mathrm{p}<0.001)$. Blood transfusion requirement was similar in both groups and no hypotensive episodes were recorded. Conclusion: Although previous studies have suggested that spinal anaesthesia reduces blood loss during prostatic resection, however, the present study fails to confirm this association.
\end{abstract}

Key words: Transurethral resection of prostate (TURP), Anaesthesia, Blood Loss

Transurethral resection of prostate (TURP) has been performed under different types of spinal, general, epidural, continuous spinal, continuous epidural anesthesia and sedoanalgesia ${ }^{1.2 .3 .4}$. There are a number of circulatory and biochemical changes which have been associated with anaesthesia and these may modify blood loss particularly in the setting of transurethral prostatic resection ${ }^{1.2 .6}$. It has also been reported that arterial pressure during anaesthesia was an important determinant of blood loss during TURP i.e blood loss smaller when average systolic pressure was 10) $\mathrm{mm} \mathrm{Hg}$ or lower".

A number of factors other than anaesthesia may influence intraoperative blood loss during transurethral resection of prostate, including vascularity of prostate, surgical technique, weight of prostate gland, length of operation and histology. Surgical technique has been thought to be the basis for observed variation in blood loss hetween surgeons with different skills. Some patients developed subclinical as well as clinical intravascular coagulopathies which were related to resected weight of prostate, however, there was no significant difference in measured coagulation variables between spinal and general ancesthetic groups ${ }^{7.8}$. Prostate cancer could produce a state (1) low grade disseminated intravascular coagulation but there is no convincing evidence to support its contribution 10 either intraoperative or post operative blood loss ${ }^{8}$

There have been a number of studies in which the effect of anaesthesia on blood loss during prostatic resection has been evaluated ${ }^{+.19-12}$. Madsen and colleagues", in a retrospective study had shown $40 \%$ reduction in blood loss under spinal anaethesia. However the effect of factors other than anaesthesia was not taken in to account. Furthermore, the resections were performed by more than one surgeon. McGowan and Smith" on the other hand prospectively randomized patients to have TURP under spinal or a general anaesthetic with either spontaneous or controlled ventilation and these authors failed to find any. difference in blood loss. Once again surgeons of different grades were involved and the effect of weight on blood loss was not reported. Finally, McKenzies" 11 finding of less blood loss under spinal anaesthetic was consistent with the two previous studies although the influence of factors other than anaesthesia was not evaluated.

The aim of the present prospective, non randomized study was to determine the independent influence of anaesthesia on intraoperative blood loss.

\section{Patients and methods:}

A total of 110 patients treated by transurethral resection. performed by one consultant urologist and a single consultant anaesthetist, were entered in to a prospective study. The mean age of patients was 71 years (range 45 91): mean age of patients receiving a general anaesthetic was 68.5 years (range 45-83), whereas it was 72.2 years (49-91) for those who received a spinal anaesthetic. Sixty five patients $(59 \%)$ presented with prostatism and 45 $(41 \%)$ with retention of urine. Ten patients were taking aspirin, which was discontinued at least 10 days before the operation, and 7 patients had their warfarin replaced by subcutaneous heparin in the perioperative period. Sixty six patients $(60 \%)$ received a spinal anaesthetic and $44(40 \%)$ had a general anaesthetic; $80 \%$ of prostatic resections were for benign and $20 \%$ for malignant disease.

Preoperative haematological measurements included haemoglobin, platelet count, electrolyte, blood urea creatinine, liver function tests (LFT), prothrombin time (P'T) and activated partial thromboplastin time. Prothrombin time and activated partial thromboplastin 
time along with complete blood count were also measured within $20 \mathrm{~min}$ of operation and $24 \mathrm{~h}$ after surgery.

The anaesthesia was preceded by intravenous infusion of Hartmann's solution. No premedication was given routinely. Patients undergoing a general anaesthetic ,received intravenous induction with thiopentone, methohexitone or propofol, analgesia with alfentanil $1 \mathrm{mg}$ and muscle relaxation with atracurium $0.5 \mathrm{mg} / \mathrm{kg}$. The trachea was intubated in all cases with the application of lignocain $10 \%$ to the larynx to minimize coughing and straining before extubation. Maintenance was with nitrous oxide and low concentration of enflurane or isoflurane and automatic ventilation to keep the systolic blood pressure just below the patients normal. In particular no techniques of induced hypotension were used.

Spinal anaesthesia was induced via the L2/3 interspace in the left lateral position with $4.0 \mathrm{ml}, 0.5 \%$ plain bupivacaine (not the commonly used hyperbaric spinal solution. This resulted in a dense and prolonged block from around T10 dermatome downwards and as the block was not usually high, it was not associated with a marked fall in blood pressure. None of our patients had required a vasopressor e.g ephedrine.

A Richard Wolf $27 \mathrm{Fr}$ continuous irrigating resectoscope was used to resect the prostate down to the capsule. No significant capsular perforation was identified. A warm $1.5 \%$ glycine solution was used as an irrigant. For each patient, weight of resected tissue, resection time, blood loss during surgery, introperative continous blood pressure monitoring and number of blood transfusions were recorded

The prostate chippings were placed in a container filled with $10 \%$ buffered formaldehyde. They were weighed 24 hours after the operation on an EKS electronic scale. This weight has been recorded as "dry weight" (13).

All effluent irrigation fluid mixed with blood and urine was collected intraoperatively in a large bucket and its exact volume was measured. The fluid was stirred and an aliquot was taken for measurement of its haemoglobin content using Coulter S+IV. This was achieved by simultaneous rapid destruction of erythrocytes and conversion of haemoglobin to a stable pigment through the use of a lysing agent, LYSE S III DIFF. The lysing agent converts most of the released haemoglobin to a stable cynide containing pigment, the absorbance of which is directly proportional to the haemoglobin concentration. The accuracy of this method is equivalent to that of the haemoglobin cynide method which is the reference method recommended for haemoglobinometry by the ICSH (International Committee for the Standarization of Haematology).Introperative blood loss was calculated by the following formula (14):

$\mathrm{Hb}$ conc. In irrigation effluent(g/dl) X

Blood Loss $(\mathrm{mls})=$

Volume of irrigation effluent ( $\mathrm{mls}$ )

Preop $\mathrm{Hb}$ conc. In blood $(\mathrm{g} / \mathrm{dl}$
The data was entered in to a statistical analysis package (-STAT) which provided results of unpaired t-test, chi square analysis, p value using Mann-Whitney test, multivariate analysis and multiple regression analysis.

\section{Results:}

The mean resection time under a general anaesthetic was $26.2 \mathrm{~min}(8-60 \mathrm{~min})$ whereas it was $30.7 \mathrm{~min}(5-69 \mathrm{~min})$ under spinal anaesthetic. There was no significant difference in resection time between two anaesthetic groups $(p=0.139)$. In addition, there was no significant difference in resection rate $(12 \mathrm{~g} / \mathrm{min}$ under spinal and 13 $\mathrm{g} / \mathrm{min}$ under general anaesthetic) between two groups.

Mean resected weight was significantly larger under spinal anaesthetic 34.3 grams $(3-100)$ than under general anaesthetic 22.8 grams (4-75), $p=0.001$. Thirty four (77.3\%) patients in the general anaesthetic (44 patients) and $54(81.8 \%)$ patients in the spinal anaesthetic group (66 patients) had benign prostatic hyperplasia whereas 10 patients $(22.7 \%)$ who had a general anaesthetic (44 patients) and $12(18.2 \%)$ patients receiving a spinal anaesthetic (66 patients) were found to have prostatic adenocarcinoma on histological examination of the resected tissue. There was no significant difference in histological diagnosis between general and spinal anaesthetic groups ( chi square $=0.091$ ).

The mean weight of benign glands was 32.0 grams and that of resected malignant prostate tissue was 20.3 grams $(p=0.003)$. There was no significant difference in the number of patients who had abnormal prothrombin time i.e $>15$ seconds between two anaesthetic groups. Mean intraoperative blood loss was significantly higher under spinal $(375.3 \mathrm{mls})$ than a general anaesthetic $(236.4$ $\mathrm{mls}), \mathrm{p}=0.0005$.

Rate of blood loss in terms of its volume (mls) lost for each gram of prostate resected was insignificant, however the loss (mls) for each minute of resection was just about significantly higher under spinal anaesthesia as shown in Table II. The mean blood loss was $211.3 \mathrm{mls}$ when resected prostate weight was $<35$.grams i.e small glands and $529.4 \mathrm{mls}$ when it was $>35$ grams. Mean blood loss was $230 \mathrm{mls}$ under spinal and $193.8 \mathrm{mls}$ under general anaesthetic when resected weight was small $(<35$ grams). Similarly, mean blood loss was $567.4 \mathrm{mls}$ in spinal and $381.2 \mathrm{mls}$ in general anaesthetic group when the $>35$ grams of prostate were resected,Fig 1 .

Mean blood loss was $413.9 \mathrm{mls}$ for patients with benign and $205.0 \mathrm{mls}$ for malignant histology of prostate resected under spinal anaesthesia. Similarly this loss was $257.3 \mathrm{mls}$ for benign glands and $165.2 \mathrm{mls}$ for malignant glands removed under general anaesthesia. Multiple regression analysis has shown that when weight of resected prostate and anaesthesia are considered separately, only weight has a significant effect on blood loss. Hence if weight factor is removed there is no 
significant effect of anaesthesia on intraoperative blood loss, Table III.

Multivariate analysis of four factors i.e resected weight, resection time, type of anaesthesia, and histology . affecting blood loss during TURP has shown a very low significance of anaesthesia suggesting that this has no effect on blood loss. Similarly histology is non significant in predicting blood loss. Therefore the two significant factors predicting blood loss are resection time and resected weight of prostate. Table IV

Table I Abnormal PT $=>15 \mathrm{sec}$ measured postoperatively

\begin{tabular}{llll} 
Anacsthesia & $\mathrm{PT}=<14$ & $\mathrm{PT} \Rightarrow>15$ & Total \\
\hline General & $28(63.6 \%)$ & $16(36.4 \%)$ & 44 \\
Spinal & $43(65.2 \%)$ & $23(34.8 \%)$ & 66 \\
\hline
\end{tabular}

Table II Comparison of Intraoperative blood loss during TURP between two anaesthetic groups

\begin{tabular}{|c|c|c|c|c|}
\hline \multirow[t]{2}{*}{ Anacsthesia } & \multirow[t]{2}{*}{$=n$} & \multirow{2}{*}{$\begin{array}{l}\text { Blood loss } \\
\mathrm{mls}\end{array}$} & \multicolumn{2}{|c|}{ Rate of blood loss } \\
\hline & & & $\mathrm{Mls} / \mathrm{g}$ & Mls/min \\
\hline Spinal & 65 & $\begin{array}{l}375.3 \\
(14 \quad 1587)\end{array}$ & $\begin{array}{l}11.9 \\
(1.0-39.4)\end{array}$ & $\begin{array}{l}12.4 \\
(1.5-43.2)\end{array}$ \\
\hline (iencral & 44 & $\begin{array}{l}236.4 \\
(6826) \\
p=(0.005\end{array}$ & $\begin{array}{l}12.9 \\
(0.6 \quad 05.6) \\
p=0.638\end{array}$ & $\begin{array}{l}9.6 \\
(0.7-35) \\
p=0.051\end{array}$ \\
\hline
\end{tabular}

Fig 1 Relationship between resected weight of prostate \& intraoperative blood loss $(\mathrm{mls})$ in two anaesthetic groups

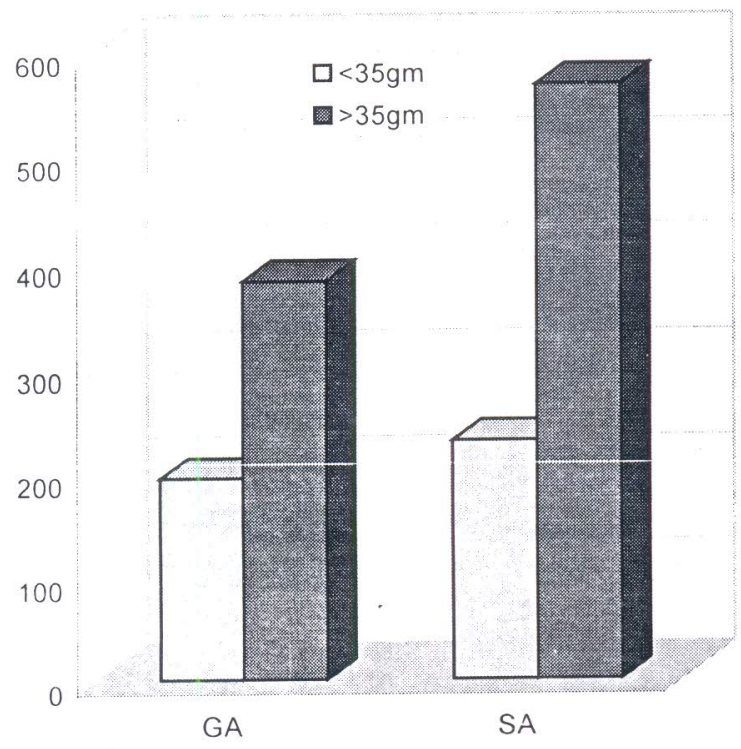

Table III Relative Significance of Anaesthesia and Resected Weight on Intraoperative blood loss during TURP

\begin{tabular}{lll} 
Factors assessed & $\begin{array}{c}t- \\
\text { significance }\end{array}$ & $P$-value \\
\hline Resected weight & $(0 .()$ & $<0.0(0)$ \\
Anaesthesia & $-1 .(1)$ & 0.28 \\
\hline
\end{tabular}

Table IV Mutivariate analysis of factors affecting blood loss during TURP

\begin{tabular}{ll}
\hline Factors & Significance \\
\hline & $P=0.024$ \\
Resection time & $P=0.18 .3$ \\
(ieneral vs spinal anaesthesia & $P=0.479$ \\
Histology of resected prostate & \\
\hline
\end{tabular}

\section{Discussion}

The effect of choice of anaesthetic technique on intraoperative blood loss during operations on lower part of the body has remained controversial. It has been speculated that the hypotension caused by the sympathetic block leads to reduced bleeding under spinal anaesthesia ${ }^{17}$. However, a variety of different factors associated with spinal as well as general anaesthesia can lead to rise in venous pressure in pelvic veins and vasodilatation in vessels of lower part of the body. Similarly use of irrigant fluid below the body temperature causing shivering and intravenous infusion of cold blood can increase venous pressure $^{18}$. Raised venous pressure during TURP increases bleeding ${ }^{19}$ but several studies have reported no significant effect of either of these anaesthetic techniques on intraoperative blood loss $4.7 .10,15 \cdot 16$. Our study has found an association between anaesthesia type and blood loss but this observation reflects the fact that large glands were more likely to be removed under general anaesthesia and hence more bleeding occurred. However, when the weight of resected prostate was taken in to account, the type of anaesthesia had no influence on introperative blood loss.

This study has confirmed the finding of previous studies that the intraoperative blood loss is very significantly associated with the weight of resected prostatic tissue $\mathrm{e}^{7,8,14.20}$. We have determined on multivariate analysis in the present study that the resected weight amongst the well documented factors has the strongest influence on blood loss. The number of patients having an abnormal prothrombin time was similar between two anaesthetic groups but an abnormal prothrombin time and activated partial thromboplastin time measured immediately after surgery was associated with resection of large prostates ${ }^{8}$. This finding is similar to the observations reported by other authors ${ }^{7}$. The prostatic tissue has a high content of proteolytic enzymes (plasminogen activators, thromboplastines etc) which are released and absorbed in to circulation during resection, causing imbalanced activation of anticoagulant system ,therefore, producing coagulopathy and excessive bleeding 7.8 .

Prostate cancer has been known to cause subacute and chronic forms of disseminated intravascular coagulation but this haematologic abnormality does not usually require any treatment ${ }^{21}$. Our study has shown that malignant prostates resected under spinal or a general anaesthetic had no effect on increasing the blood loss. This has also been reported by other authors ${ }^{7.18}$.

In conclusion, spinal anaesthesia is not associated with reduced blood loss and there is no significant effect of 
either general or spinal anaesthesia on the amount of bleeding during TURP.

\section{Acknowledgements :}

We are grateful to $\mathrm{Dr} \mathrm{CJ}$ Gibson ,PhD for his help with statistical analysis.

\section{References}

1. Reisli R, Celik J, Tuncer S, et al. Anaesthetic and haemodynamic effects of continuous spinal versus continuous epidural anaesthesia with prilocaine. Eur $J$ Anaesthesiol. 2003 Jan;20(1):26-30

2. Hahn RG. Blood volume at onset of hypotension during TURP performed under epidural anaesthesia. Eur $J$ Anaesthesiol 1993; $10(3): 219-25$

3. Birch BR, Gelister JS, Parker CJ, et al. Transurethral resection of prostate under sedation and local anaesthesia (sedoanalgesia). Experience in 100 patients. Urology 1991 $: 38(2): 113-8$

4. Nielsen KK, Andersen J, Asbjorn J, et al. Blood Loss in transurethral prostatectomy : epidural versus general anaesthesia. Int Urol. and Nephrol 1987; 19 (3) : $287-292$

5. Ekengren J, Hahn RG. Blood loss during transurethral resection of the prostate as measured by the HaemoCue photometer. Scand J (Irol Nephrol 1993;27:501-7

6. Hahn RG. Dilution of blood proteins due to irrigant absorption in transurcthral prostatic resection. Scand J Urol Nephrol 1989;23(2): 97-102

7. Smyth R, Cheng D, Asokumar B ct al. Coagulopathies in patients after transurethral resection of the prostate : spinal vs general anaesthesia. Anaesth Analg 1995; 81: 680 - 5

8. Ahsan Z, Cartner R and English PJ. Coagulation tests in predicting haemorrhage after prostatic resection. $\mathrm{Br} J$ Urol 1993:72,2()1 - 206
9. Madsen RE, Madsen PO. Influence of anaesthesia form on blood loss in transurethral prostatectomy. Anaesth. \& Analg. $1967 ; 46(3): 330-32$

10. McGowan SE and Smith GFN. Anaesthesia for transurethral prostatectomy. Anaesthesia 1980; 35: $847-853$

11. Mackenzie AR. Influence of anaesthesia on blood loss in transurethral prostatectomy. Scot Med J 1990;35:14-16

12. Abrams $\mathrm{PH}$, Shah PJR, Bryting $\mathrm{K}$ et al. Blood loss during transurethral resection of the

13. prostate. Anaesthesia 1982; 37: $71-73$

14. Baker JR. Primary fixatives considered separately to non coagulants. Principles of Biological Microtechniques, ed 2. Baker JR, chapter 6, pp $111-116$. London :Methuen

15. Fujita K.Factors influencing bleeding during transurethral prostatectomy. Clinical Therapeutics. 1988; 10:16-19

16. Fraser I, Scott M, Campbell I et al. Routine cross matching is not necessary for a transurethral resection of prostate. $\mathrm{Br} . J$ Urol $1984 ; 56: 198$

17. Slade N, Andrews G, Tovey GH et al.Blood loss in prostatic surgery. BrJ Urol 1964;36: 399.

18. Covino BG. Rationale for spinal anaesthesia. Imt Anaesthesiology Clinics; 27(1): $8-12$

19. Drewinko B, Cobb P, Guinee $V$ et al. Untreated prostatic carcinoma is not associated with frequent thrombohemorrhagic disorders. Urology $1987 ; 30: 11-7$

20. Desmond $J$. Complications of transurethral prostatic surgery. Canadian Anaesthetists' Society Journal 1970: 17: $25-36$

21. Lewi HJE, Hales DSM, Mahmoud et al. The characteristics of post TUR blood loss: A preliminary study. Urol Res, $1983 ; 11: 29-31$

22. Ross G, Thompson I and Samaha RJ. Subacute intrvascular coagulation with prostatic carcinoma. Mo. Med 1974;71: $177-79$. 